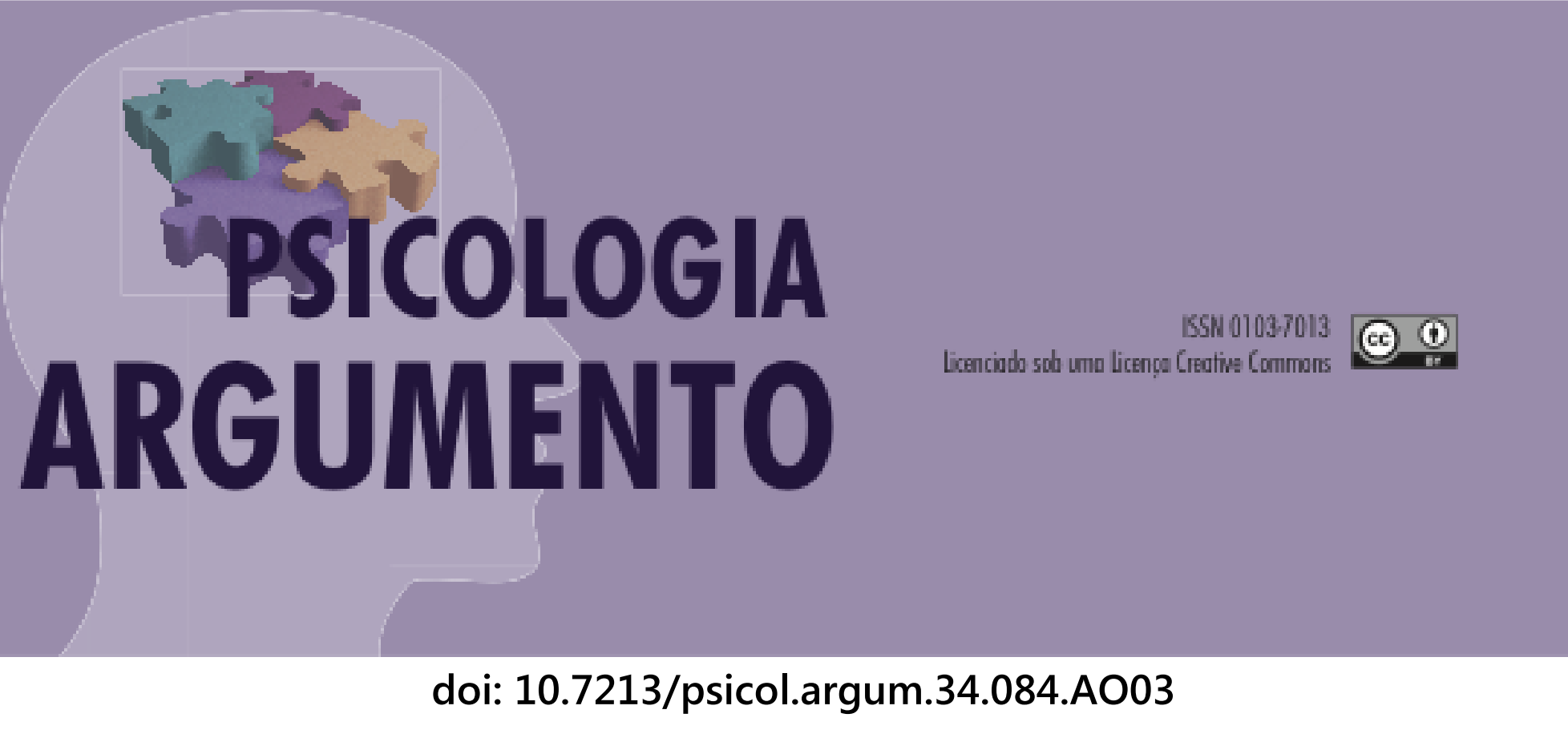

\title{
A respeito do conceito de potência na prática clínica: leituras deleuzianas
}

Regarding the concept of potency in practice clinic: readings of Gilles Deleuze

Sonia Regina Vargas Mansano[a]

[a] Doutora em Psicologia Clínica pela PUC/SP. Docente do Programa de Pós-graduação em Administração e do Departamento de Psicologia Social e Institucional da

Universidade Estadual de Londrina. Londrina, PR - Brasil, e-mail: smansano@sercomtel.com.br

\section{Resumo}

A presente pesquisa teórica buscou investigar como o conceito de "potência", presente nos estudos de Gilles Deleuze, coopera para compreender a prática clínica, englobando tanto a experiência dos encontros quanto às variações de potência que eles produzem no corpo. Tais encontros poderão ganhar contornos decisivos quando, por intensificação, provocam abalos, dúvidas, novas conexões e/ou rupturas para com os modos de vida já conhecidos, convocando o sujeito a problematizar sobre seus modos de existência. Seguindo os estudos deste autor, pode-se compreender o quanto a prática clínica é inseparável de uma prática crítica. 
Ambas acontecem em meio a diferentes problematizações sobre acontecimentos e encontros que emergem ao acaso, bem como sobre os modos de vida que são inventados e colocados em circulação no decorrer de uma existência. Foi com essa perspectiva que se buscou tecer algumas articulações entre o conceito de potência e a prática clínica.

Palavras-chave: Clínica. Potência. Afeto

\begin{abstract}
Present research looked for to investigate as the "potency" concept, present in Gilles Deleuze's studies, cooperates to understand as much the encounters as for the potency variations that they unchain in the body. Such encounters can win decisive outlines when, for intensification, they provoke disturbances, doubts, new connections and/or ruptures to the life manners already known, summoning the subject to problematize on their existence manners. Following this author's studies, it can be said that the clinical practice is inseparable of a critical practice. She happens amid different events and encounters that emerge at random, as well as on the life manners that are invented and put in circulation in elapsing of an existence.
\end{abstract}

Keywords: Clinical. Potency. Affection.

\title{
Introdução
}

Em diversos momentos de sua obra, Gilles Deleuze refere-se à clínica como uma possibilidade de expansão e potencialização da existência. Para ele, os encontros e misturas que são experimentados no cotidiano podem perturbar uma existência organizada, lançando os sujeitos em problematizações sobre os modos de viver. Dependendo da maneira como essa desorganização é experimentada, diferentes questões ganham espaço de expressão uma vez que o verbo "viver" pode ser praticado de inúmeras maneiras. Essa desorganização pode fazer com que a clínica (ao mesmo tempo crítica) seja acionada (Deleuze, 1997). Falamos, então, de uma clínica que não se restringe ao encontro entre dois indivíduos no setting analítico. Sua condição de possibilidade está nos encontros e nas intensificações afetivas que eles produzem. Assim, um encontro inesperado, aparentemente banal, pode nos lançar em um campo problemático povoado por questões que nos deslocam daquilo que acreditávamos ser; deslocamento este que não é isento de certa crueldade, visto que põem em xeque os modos de viver já conhecidos. É nesse campo que a clínica, como disparadora de problemas, dá seus primeiros passos: lá mesmo onde a vida extrapola seus limites, gera assombros e impõe questões - sendo que estas, ocasionalmente, poderão vir a ser apreciadas na companhia de um psicoterapeuta.

Foi nesta perspectiva que o presente estudo ganhou contornos. Seu objetivo consiste em percorrer um caminho conceitual ao longo do qual a prática clínica possa ser pensada em sua dimensão social e crítica, que acolhe, mas que também produz questões, podendo tornar-se uma prática aliada da potência. Para isso, partiremos de um breve ensaio diagnóstico sobre o presente e, valendo-nos dele, percorreremos algumas leituras e estudos realizados pelo filósofo francês Gilles Deleuze, buscando traçar algumas passagens entre as noções de "potência" e "clínica". 


\section{A naturalização das paixões tristes}

É notável o quanto a vida contemporânea está cada vez mais submetida aos axiomas que compõem o modo capitalista de produção. Tais axiomas funcionam ao descodificar diferentes dimensões da existência que outrora estavam ligadas a valores sociais, afetos, sensibilidade e encontros, integrando-os, agora, diretamente à rede de produção econômica que, por sua vez, buscará lhes atribuir valor monetário. Assim, nota-se que os axiomas colocados em circulação pelo capitalismo se renovam a cada instante, abrindo um leque amplo de negociações, uma vez que qualquer objeto ou relação pode ser, em nossos dias, uma fonte para produção econômica. É nesse sentido que Deleuze e Guattari assinalam a presença de uma grande "flexibilidade na axiomática do capitalismo" que está "sempre pronto a ampliar seus próprios limites para acrescentar mais um axioma a um sistema já saturado" (2010, p. 317).

Os efeitos deste empreendimento são diversos e, dentre eles, pode-se destacar as agendas lotadas, as metas em curto prazo a serem cumpridas na esfera do trabalho e os encontros afetivos cada vez mais atravessados por formas de controle e negociações financeiras. Neste contexto, o verbo "dever" ganha os mais diversos contornos imperativos que se objetivam em prescrições que preenchem o dia e que, em larga medida, tornam-se obrigações vazias a serem simplesmente reproduzidas. Para dar conta de cumprir esses compromissos, a vida tende a ser fixada em territórios mais conhecidos e avaliados como seguros. Isso porque "o regime de descodificação" capitalista "não significa, seguramente, ausência de organização, mas a mais sombria organização, a mais dura contabilidade, a substituição dos códigos pela axiomática" (2010, p. 204-205). Cabe perguntar, então, pelos efeitos, na vida dos indivíduos, desta maneira tão cronometrada e controlada de viver

Um importante efeito a ser notado neste processo é que o corpo pode ficar separado daquilo que é capaz (potência). Quando esta separação acontece, passa-se a acreditar que um outro (exterior) seja responsável tanto por elaborar uma série de prescrições a serem simplesmente reproduzidas, quanto por prover as demandas que lhe são solicitadas. Neste caso, corre-se o risco de cair no universo das paixões tristes e, para Deleuze: "o próprio da paixão, em qualquer caso, consiste em preencher a nossa capacidade de sermos afetados, separando-nos ao mesmo tempo de nossa capacidade de agir, mantendo-nos separados desta potência" (Deleuze, 2002, p. 33).

Na paixão, a potência passa a ser atribuída a quem está fora. Mas quem seria esse outro (externo) dotado de tamanho poder? Em um cenário capitalista, fica muito fácil forjálo, por exemplo, convidando a população a consumir produtos e/ou serviços que lhe são apresentados como solução rápida e que teriam a capacidade de solucionar os problemas. Como essa rapidez e perspicácia é apenas uma promessa (de mercado), as queixas, reclamações e frustrações diante de seu não cumprimento logo se multiplicam. Com isso, "geralmente as pessoas fazem a soma de seus males, é mesmo aí que a neurose começa, ou a depressão, quando nós nos metemos a somar" as tristezas (Deleuze, 2009, p. 20). Estaríamos vivendo uma naturalização das paixões tristes? Para levar adiante esta suspeita, cabe dar visibilidade às situações mais cotidianas nas quais ela tende a se efetuar. $\mathrm{E}$, para isso, percorreremos aqui três linhas descritivas que ajudam a traçar este diagnóstico.

Comecemos pela linha dos relacionamentos amorosos que, em casos diversos, tomaram contornos daquilo que Deleuze descreve como "cenas domésticas". Seu pressuposto é: "faça-me mal, entristeça-me que eu te entristeço" (Deleuze, 2009, p. 64). 
Atualizam-se, nesse jogo, diferentes paixões tristes como o ressentimento, a cobrança, o julgamento e o ódio entre os parceiros, mas também para com aqueles que acompanham o desenrolar da relação (como os filhos, os amigos e os conhecidos). Tais encontros tendem à decomposição de seus partícipes e desta decomposição é extraída uma forma entristecida de existir. Incapazes de perceber a que tipo de demanda estão servindo, os amantes seguem o curso de suas existências enredados na decomposição naturalizada de si e dos outros. Daí ser tão comum escutarmos enunciados como: "família sem briga não é família", ou, "se não há cenas de ciúmes, não há amor”. Deleuze acrescenta que essa disseminação naturalizada das paixões tristes tem uma dimensão contagiosa: "eles não soltarão você enquanto não tiverem inoculado sua tristeza" (Idem, p. 64).

A cena doméstica de um familiarismo culpabilizante e servil, que tanto incomodou Deleuze em seus estudos, se propaga para uma segunda linha diagnóstica a ser aqui considerada: o contexto laboral. Este, por vezes, é marcado por intrigas, competição, intolerância e pela necessidade de permanecer conectado a esses afetos tristes em função da estabilidade do emprego, da manutenção de uma posição funcional conquistada e/ou do retorno financeiro mais ou menos garantido. Na esfera do trabalho, vive-se uma espécie de desconfiança que se manifesta no descrédito em relação ao coletivo e às conexões que nele são realizadas. A situação é agravada diante da proliferação do chamado trabalho imaterial (Hardt \& Negri, 2001), que exige dos profissionais a disponibilidade afetiva para oferecer atenção, cuidados, escuta e acolhimento aos seus clientes. Quando essas dimensões afetivas tornam-se obrigações laborais que são prescritas e avaliadas de maneira quantitativa, o que se vê é a dificuldade de dar acolhida aos encontros e seus afetos. Assim, com outros contornos, novamente encontramos a emergência de paixões tristes. Afinal, essas deliberações sobre as maneiras "corretas" de se relacionar vêm de fora, por vezes prescritas como funções a serem realizadas à revelia da disponibilidade afetiva do trabalhador em questão. Nota-se que o encontro profissional prescrito não prevê a ampla variedade afetiva gerada pelo acaso dos encontros e a possibilidade recorrente de que aconteçam desentendimentos e desavenças entre os envolvidos. Entretanto, como elas sempre correm o risco de se manifestar, as restrições e sanções são logo colocadas.

Ao sair do contexto laboral, esgotado pela necessidade de atuar de maneira performática nos encontros profissionais prescritos, a disponibilidade para estar com o outro tende a se esvair. E, quando as relações da vida privada e suas questões ganham espaço, os especialistas são logo solicitados a se manifestar. Eles são diversos e provêm de áreas como a saúde, a estética, a economia, a educação e a própria psicologia, para citar apenas alguns exemplos. Aceitando uma posição legitimada de autoridade prescritiva (que, vale ressaltar, não é simplesmente adotada por eles, mas também requerida pelo conjunto de indivíduos que os procuram ávidos por soluções rápidas para seus problemas) tais profissionais são solicitados a dizer qual o melhor caminho para educar crianças, ter uma boa saúde, andar na moda, fazer bons negócios financeiros, ter a autoestima fortalecida, enfim, estes profissionais são chamados a prescrever novas normas para a existência. Nessa terceira linha das relações pessoais, o que encontramos novamente são as paixões tristes que ganham espaço à medida que colocam como referência do viver algo ou alguém externo, investido de autoridade e que passa a ser consultado sobre a banalidade de pequenas rotinas. Quando a potência é atribuída a um agente externo que decide e indica os melhores caminhos, a ação do sujeito enfraquece, e isso tende a favorecer o endurecimento das certezas e a espera por dias melhores. 
A breve descrição destas três linhas deixa entrever o risco anteriormente colocado: o de, no decorrer deste estudo, ficarmos presos à lista das paixões tristes, caindo em generalizações vazias e fortalecendo a sua naturalização. Não há dúvidas de que os encontros que decompõem, constrangem e geram tristeza estão presentes no curso de uma existência e, por diferentes vias, também a coloca em movimento. A questão que se impõe, então, consiste em verificar, a cada caso, qual "é o valor que lhe damos" (Deleuze, 2009, p. 64), levando-se em conta que, em sua obra Nietzsche e a Filosofia (1976), Deleuze esclarece que a própria valoração implica um poderoso jogo de forças. Assim, a atribuição de valores e a avaliação do vivido é disputada por forças que não cessam de guerrear. Tomando este combate em análise, torna-se relevante perguntar pela parcela de vida lhe é concedida e que tipo de existência essa concessão permite. Será que estamos cultivando e disseminando a tristeza nas situações mais insuspeitas e inocentes? E, se assim for, em quais momentos torna-se possível resistir e insistir nas questões trazidas por Deleuze sobre como escapar desse tipo de encontro? (Deleuze, 2009).

Ora, pensar a prática clínica em um contexto social que tende a naturalizar as paixões tristes, exige a abertura para uma verdadeira batalha que, em um primeiro momento, teria como tarefa dar visibilidade a essas paixões, bem como aos diferentes questionamentos que elas colocam em curso. Não há, portanto, um estado puro de tristeza uma vez que mesmo no pior dos mundos haverá alegrias pulsando. Deleuze convida-nos, então, a pensar por um outro ângulo: "em lugar de fazer a soma de nossas tristezas, tome um ponto de partida local sobre uma alegria com a condição de que nós sintamos que ela nos concerne verdadeiramente" (Deleuze, 2009, p. 20). Como se dá esta ruptura?

\section{A respeito da noção de potência nas leituras de Gilles Deleuze}

Seguindo as considerações de Deleuze, cabe atentar para as possibilidades de ruptura (em relação a esta naturalização) que são ensaiadas e colocadas em movimento. Para compreender a noção de potência, comecemos por suas conversações com Espinosa. Nelas, Deleuze mostra que a potência é indissociável da noção de ato. Há imanência entre potência e ato, sendo que cada ato realizado dá testemunho de um grau de potência do corpo. Assim, "toda potência é ato, ativa, e em ato" (Deleuze, 2002, p. 103). Por isso mesmo, não possuímos uma potência de antemão uma vez que ela não se restringe a uma posse pessoal ou a um estado fixo.

Sendo a potência imediatamente ato, cabe investigar o conjunto de condições sob as quais ela pode ser efetuada, ou seja, condições nas quais é possível agir e exercer o poder do corpo tanto de afetar quanto de ser afetado. Falamos, então, de um campo de forças no qual o verbo "viver" pode ser experimentado de múltiplas maneiras. Nessa multiplicidade, cada ação experimentada atesta um grau de potência do corpo.

Assim, nota-se que o corpo é bastante evocado nos estudos de Deleuze a respeito de Espinosa. Com esses autores, compreende-se a potência do corpo por aquilo que ele pode, aquilo que ele pode em ato. Portanto, a potência é variável e efetua-se nos encontros, nos cortes que eles precipitam e que fazem o corpo transitar de um grau a outro. Como cada problema enfrentado envolve um jogo de forças diferenciado, é a cada situação que posso apreciar a potência/ação do corpo. Assim, o sujeito não está dado em uma estrutura fixa, mas é produzido em um movimento incessante de variação da potência. 
Por que estamos tão distantes da compreensão da potência do corpo e de suas variações? Para Espinosa, na cotidianidade dos encontros é comum nos atermos apenas aos efeitos que eles produzem, sem compreender suas causas. $\mathrm{Na}$ impossibilidade dessa compreensão, a consciência segue julgando o vivido, valendo-se do que Espinosa chama de “ideias inadequadas" (1983, p. 177). Pode-se dizer que aquela vida cronometrada, mencionada no início deste trabalho, em larga medida colabora para aumentar a distância em relação à compreensão das causas.

Deleuze dá um passo adiante na compreensão da noção de potência: Se a cada encontro vive-se uma variação no poder do corpo para afetar e ser afetado, pode-se dizer que o "eu" flutua entre os graus de potência, experimentando, assim, uma "linha melódica da variação contínua" (Deleuze, 2009, p. 26). Essa variação acontece por meio de dois movimentos distintos. Quando um encontro aumenta a potência do corpo, há nele uma composição, pois o corpo externo com o qual me encontro "compõe diretamente a sua relação com o nosso, e, com toda ou com uma parte de sua potência, aumenta a nossa" (Deleuze, 2002, p. 28). Nesse momento, a potência é preenchida de maneira a produzir alegria e a tornar o corpo ainda mais perfeito, uma vez que está mais próximo da ação.

Já quando o encontro é ruim, ocorre uma diminuição da potência, ou seja, "um corpo decompõe a relação" constitutiva "do nosso, ainda que se componha com as nossas partes, mas sob outras relações que aquelas que correspondem à nossa essência: por exemplo, como um veneno que decompõe o sangue" (Deleuze, 2002, p. 28). Assim, o mau encontro separa o corpo daquilo que ele pode. Primeiro, porque essa mistura decompõe as partes constituintes desse corpo e faz com que ele seja menos perfeito em sua capacidade de afetar e de ser afetado. Em segundo lugar, porque uma parte da energia passa a ser gasta para afastar aquilo que entristece e que tende a destruir a composição atual. Com isso, o investimento desejante na ação e na alegria acaba sendo fixado nas paixões tristes, diminuído ou até mesmo imobilizado. O corpo defende-se, produzindo uma espécie de endurecimento afetivo, a fim de manter à distância aquilo que o decompõe. Separado do poder de afetar e ser afetado, o sujeito fica ainda mais longe da potência.

Com Espinosa e Deleuze é possível colocar a seguinte questão: estaríamos sujeitados ao acaso dos encontros, submetidos àquilo que vem de fora e que ora entristece, ora alegra? Eles falam, então, da possibilidade de avançar para a compreensão das causas dessa variação, buscando um entendimento daquilo que convém ou não convém ao corpo. Daí a insistência de Deleuze (2002) em retomar a questão espinosana: o que pode um corpo? Pensar na noção de potência implica uma análise prática sobre o vivido, atenta às mudanças, às variações, aos mínimos gestos pelos quais o corpo torna-se capaz de compreender as causas da variação de potência. Afinal, o que se passou em um dado encontro para que algo (uma ação) fosse desbloqueado? O que aconteceu para que o corpo passasse a fazer algo que, até então, estava impedido de fazer? Atendo-se aos mínimos gestos que não podiam ser praticados e que agora passam a ser, a clínica funciona como veículo que diversifica o movimento e a experimentação do verbo "viver". Nota-se que as questões acima circunscrevem um campo de problemas que diz respeito também às misturas e aos deslocamentos afetivos. Nesse campo, as ideias deixam de ser inadequadas e torna-se possível sair do mero julgamento dos encontros para compreender as causas daquilo que aumenta ou diminui a potência. Pode-se dizer que, nesses deslocamentos, o corpo já está mais próximo do ato e da possibilidade de intervir sobre o vivido. 
Avançando nesse movimento de compreensão das causas torna-se possível selecionar os encontros, considerando àquilo que convém ou não ao corpo. Mas, diz Deleuze, "essa seleção é muito dura, muito difícil. É que as alegrias e as tristezas, os aumentos e as diminuições, os esclarecimentos e os assombreamentos costumam ser ambíguos, parciais, cambiantes, misturados uns aos outros" (1997, p. 163). Qual seria, então, o critério de seleção a ser utilizado? É aí que podemos retornar às considerações dos autores sobre a alegria. Somente ela conecta o corpo à potência, pois necessariamente vai aumentá-la, tirando o corpo da passividade e da conformação. Isso só pode ser experimentado quando o corpo é capaz de atentar para as misturas, para as variações e para as possibilidades de seleção dos encontros que o compõe, deixando-o mais ativo. Deleuze alerta que essa seleção não envolve apenas "o esforço pessoal que cada um deve fazer sobre si mesmo (Razão), mas uma luta passional, um combate afectivo inexpiável em que se corre risco de vida, onde os signos afrontam os signos e os afectos se entrechocam com os afectos, para que um pouco de alegria seja salva, fazendo-nos sair da sombra (Deleuze, 1997, p. 163)".

Obviamente, no decorrer de uma existência não há possibilidade de selecionar apenas os encontros alegres. Sempre haverá o jogo de forças que se afirma também no acaso, no necessário e no trágico. De qualquer maneira, ambos (Deleuze e Espinosa) consideram que a alegria, também nesses casos, é uma grande aliada da potência, pois mesmo diante do que é adverso, a ação é possível. Vale repetir que ao invés de fazer a lista das tristezas - com a qual já estamos tão acostumados - torna-se precioso dar passagem à alegria.

A dificuldade que se configura nessa tarefa está em detectar em quais circunstâncias as paixões tristes estão atuando e os momentos em que elas precisam ser combatidas para dar consistência a uma prática clínica. Nas leituras sobre Espinosa, Deleuze explora alguns caminhos questionando:

1. Como chegar ao máximo de paixões alegres e daí passar aos sentimentos livres ativos (uma vez que nosso lugar na Natureza parece nos condenar aos maus encontros e às tristezas)? 2. Como conseguir formar idéias adequadas, de onde decorrem, precisamente, os sentimentos ativos (uma vez que nossa condição natural parece nos condenar a ter tão-somente idéias inadequadas do nosso corpo, do nosso espírito e das outras coisas)? 3. Como devir consciente de si mesmo, de Deus e das coisas - "sui et Dei et rerum aeterna quadam necessitate conscius" (uma vez que nossa consciência parece inseparável de ilusões)? (Deleuze, 1992, p. 34).

O que está colocado nestes questionamentos é precisamente a relevância de uma prática problematizante a ser desencadeada na clínica. Nesse sentido, cabe dizer que há um outro passo a ser dado para além da compreensão das causas e da seleção dos encontros: a possibilidade de dobrar as forças do fora, inclusive aquelas que geram tristeza, valendo-se da potência de ação e criação. Isso, sem dúvida, envolve uma conquista: como a potência não permite posse, pois é mutável e varia a cada ato realizado, o que ganha evidência nos diferentes encontros é o conjunto de condições sob as quais cada sujeito pode efetuá-la e esforçar-se para dobrar as forças do fora, estendendo ao máximo o poder de afetar e ser afetado. Diz Deleuze:

Se ao longo de nossa existência soubermos compor essas partes de maneira a aumentar a nossa potência de agir, experimentamos então por isso mesmo muitas afecções que dependiam unicamente de nós mesmos, isto é, da parte intensa de nós mesmos. Se, ao contrário, não 
cessamos de destruir ou de decompor nossas próprias partes e as dos outros, nossa parte intensa ou eterna, nossa parte essencial, só tem e apenas pode ter um número ínfimo de afecções que dela mesma provêm e nenhuma felicidade que dela despende (Deleuze, 2002, p. 47-48).

\section{Qual a potência da prática clínica hoje?}

Se, como já dito, um campo problemático ganha visibilidade à medida que o corpo avança na compreensão das causas daquilo que lhe afetou e produziu incômodos, uma das condições de possibilidade da clínica está nas misturas cotidianas com o outro. Assim, um trabalho clínico começa a dar seus primeiros passos bem antes da vinda do paciente ao consultório ou à instituição. $\mathrm{O}$ socius e suas múltiplas forças díspares são de grande importância, uma vez que a clínica começa nos encontros e tem todo seu trabalho voltado para eles.

Como poderíamos, então, pensar o problema da potência em situação clínica hoje? Seguindo essa perspectiva de análise, a clínica pode ser compreendida como um lugar de apreciação de problemas, ou seja, das questões que emergem naqueles encontros suficientemente fortes que deslocam o sujeito de suas territorialidades (hábitos, valores, preferências), produzem incômodos e que o levam a pensar não sobre quem ele é, mas especialmente, sobre o que pode vir a ser.

A clínica ocupa-se, portanto, de acompanhar a variação da potência daquele corpo que já não encontra mais sossego nas certezas que até então respondiam de maneira satisfatória às inquietações e exigências identitárias. Entretanto, retomando o traçado diagnóstico feito no início deste estudo, vale dizer que muitos são os que chegam à clínica, tomados por uma peculiaridade das paixões tristes: aquela que se manifesta ao depositar no outro, que neste caso é o analista, a responsabilidade por indicar alternativas, fazendo prescrições "eficientes" para dar fim ao sofrimento e respondendo à temporalidade acelerada das soluções tão festejadas pela produção capitalista. Apresentando a demanda por resoluções imediatas - cuja fonte é o fora - e com a necessidade urgente de livrar-se dos incômodos que atormentam aquela estabilidade tão investida, novamente vemos o quanto o corpo está separado da potência de ação e mergulhado no pathos triste.

É neste momento que a prática clínica pode afirmar sua diferença política para com alguns valores que atravessam este tempo histórico: os problemas enfrentados no decorrer de uma vida não se limitam às suas soluções. E, portanto, ao se voltar para a apreciação do campo problemático, a clínica está longe de ser o lugar que resolve problemas ou reconstitui o equilíbrio. Deleuze diz:

Devemos, assim, romper com um longo hábito de pensamento que nos faz considerar o problemático como uma categoria subjetiva de nosso conhecimento, um momento empírico que marcaria somente a imperfeição de nossa conduta, a triste necessidade em que nos encontramos de não saber de antemão e que desapareceria com o saber adquirido. $\mathrm{O}$ problema pode muito bem ser recoberto pelas soluções, nem por isso ele deixa de subsistir na Idéia que o refere às suas condições e organiza a gênese das próprias soluções. Sem essa Idéia as soluções não teriam sentido (Deleuze, 2000, p. 57). 
Ao ser compreendida como uma prática que acolhe, aprecia e sustenta os problemas, a clínica coloca em movimento as questões, mudando os problemas de lugar ou mesmo criando-os. A potência da clínica, portanto, está no não saber e nas interrogações que ele suscita. Assim, seja qual for a dor ou dificuldade que tenha levado o sujeito à clínica, esta pode vir a desencadear um exercício de problematização que passa pela invenção de diversas soluções, mas que não se reduz a nenhuma delas em especial, uma vez que a solução definitiva inexiste. Cabe dizer, portanto, que há uma espécie de antiprodução na clínica, que envolve um demorar-se na apreciação dos encontros, dos sinais de potência, das misturas e afetos singulares que são experimentados por aquele corpo, sem que isso culmine em uma solução definitiva. Isso porque a clínica é praticada em meio à outra questão: "Que posso vir a ser nesses encontros que, até agora, ajudaram a fazer de mim isso que sou?" Diante desse desconhecimento, é possível ensaiar diversas saídas, sem que estas suprimam a questão. Nesse sentido, cada saída experimentada envolve uma composição provisória de si, uma criação.

Torna-se possível afirmar, então, que a prática clínica parte do campo problemático e tem nele sua condição de possibilidade uma vez que o verbo viver pode ser experimentado e apreciado por diferentes ângulos. Ampliar esses ângulos pode ser considerado um exercício clínico de aprendizagem e invenção. É nesse sentido que as certezas sobre si e sobre o outro distanciam os partícipes de um trabalho clínico, uma vez que se voltam ao julgamento prescritivo e à sentença moral sobre qual o "bom caminho" a ser seguido.

Tentando afastar-se deste risco, como é possível desteritorializar-se das tristezas (diminuição da potência) que estão demasiadamente coladas à vida? Como raspar essas amarras e bloqueios em favor da criação de outras possibilidades de existir? Deleuze e Guattari assinalam: "devemos procurar em cada caso o que passa do fluxo de intensidade, o que não passa, o que faz passar ou impede de passar" (Deleuze \& Guattari, 2010, p. 217). É assim que uma prática clínica se desenha para esses autores: ao cartografar as linhas de passagem, as linhas de bloqueio, bem como suas intensificações afetivas. Nessas investigações, a vida apresenta-se como algo que é da ordem do problemático, uma vez que

as soluções não suprimem os problemas, mas aí encontram, ao contrário, as condições subsistentes sem as quais elas não teriam nenhum sentido, as respostas não suprimem de forma alguma a pergunta, nem a satisfazem e ela persiste através de todas as respostas. Há, pois, um aspecto pelo qual os problemas permanecem sem solução e a pergunta sem resposta. (Deleuze, 2000, p. 59).

\section{Considerações finais}

Chegando ao final deste percurso investigativo, já é possível notar que ao tentar fazer algumas pontes entre a noção de potência e a prática clínica, deparamo-nos com uma multiplicação de questões. Talvez seja precisamente essa a potência que dá consistência à prática clínica: abster-se das respostas corretas e das convicções prescritas para colocar em curso uma prática que cria e que transita por problemas e respostas, parciais e provisórios. Assim, uma clínica que acolhe o campo problemático ganha consistência à medida que espalha questões. Mas, vale insistir no que diz Deleuze: "a potência das questões vem 
sempre de uma outra parte que não das respostas e desfruta de um livre fundo que não se deixa resolver" (Deleuze, 2009, p. 183).

Fazer da prática clínica uma aliada da potência do viver requer uma compreensão política tanto das múltiplas forças que atravessam a existência quanto da potência que cada uma delas coloca em movimento. Os corpos que participam do encontro clínico (seja na condição de paciente ou de terapeuta) experimentam, o tempo todo, as variações de potência e os limites para apreciar cada problema que entra em pauta. Nas passagens de um problema a outro ocorre a incessante produção dos sujeitos e dos modos de vida. Pode-se dizer, então, que a prática clínica poderá ser mais potente quanto mais manter-se atenta aos encontros, às produções desejantes e aos efeitos de variação gerados pela potência de afetar e ser afetado dos seus partícipes.

\section{Referências}

Deleuze, G. Nietzsche e a Filosofia. Tradução de Edmundo Fernandes Dias. Rio de Janeiro: Editora Rio, 1976.

Deleuze, G. Crítica e Clínica. Tradução de Peter Pál Pelbart. S. Paulo: Editora 34, 1997.

Deleuze, G. Lógica do Sentido. Tradução de Luiz Roberto Salinas Fortes. São Paulo: Editora Perspectiva, 2000.

Deleuze, G. Espinosa: filosofia prática. Tradução de Daniel Lins e Fabien Pascal Lins. São Paulo: Escuta, 2002.

Deleuze, G. Diferença e Repetição. Tradução de Luiz Orlandi e Roberto Machado. São Paulo: Edições Graal, 2006.

Deleuze, G. Cursos sobre Spinoza (Vincennes, 1978-1981) Tradução de Emanuel Fragoso, Francisca Castro, Hélio Rebello e Jéferson Aquino. Fortaleza: EDEUCE, 2009.

Deleuze, G. \& Guattari, F. O Anti-Édipo: Capitalismo e esquizofrenia. Tradução de Luiz B. L. Orlandi. São Paulo: Editora 34, 2010.

Hardt, M. \& Negri, A. Império. Tradução de Berílio Vargas. Rio de Janeiro: Record, 2001. Spinoza, B. Espinosa - Coleção Os Pensadores. Tradução de Marilena Chauí. São Paulo: Abril, 1983. 